\title{
PENGGUNAAN METODE MNEMONIC UNTUK MENINGKATKAN KEPATUHAN AKSEPTOR DALAM MENGKONSUMSI PIL KB
}

\author{
The Effect of the mnemonic method on maternal adherence in consuming oral \\ contraceptive pill \\ Diah Eko Martini ${ }^{1}$, Silvya Putri Ramadhani ${ }^{2}$ \\ ${ }^{1,2}$ Dosen Fakultas Kesehatan Universitas Muhammadiyah Lamongan \\ Alamat Korespondensi : Fakultas Kesehatan Universitas Muhammadiyah Lamongan \\ Jl. Plalangan Plosowahyu Km 02 Lamongan, Jawa Timur - Indonesia \\ E-mail : diahekomartini@gmail.com
}

\begin{abstract}
ABSTRAK
Pil KB merupakan salah satu alat kontrasepsi yang banyak diminati oleh akseptor KB karena alat kontrasepsi ini sangat efektif dan kesuburan dapat langsung kembali bila penggunaan di hentikan, namun angka kegagalannya juga cukup tinggi akibat ketidakpatuhan dalam jadwal mengkonsumsi Pil KB. Oleh karena itu diperlukan suatu metode yang tepat untuk meningkatkan kepatuhan sehingga angka kegagalan bisa diminimalisir. Tujuan dari penelitian ini adalah mengetahui pengaruh metode mnemonic terhadap kepatuhan ibu dalam mengkonsumsi pil KB di Kecamatan Ngimbang Kabupaten Lamongan.

Desain penelitian menggunakan pra-eksperimental design dengan pendekatan one group pre test and post test design. Populasinya adalah seluruh ibu yang mengkonsumsi pil KB di Kecamatan Ngimbang kabupaten Lamongan dengan jumlah sampel sebanyak 33 akseptor Pil KB yang diambil berdasarkan simple random sampling. Instrument menggunakan kuesioner terbuka dan data dianalisis dengan menggunakan uji MC Nemar.

Hasil penelitian menunjukkan sebelum diberikan metode mnemonic dari 33 responden sebagian besar (64\%) tidak patuh dalam mengkonsumsi Pil KB. Setelah diberikan metode mnemonic hampir seluruhnya (94\%) patuh dalam mengkonsumsi Pil KB. Berdasarkan hasil diatas sehingga nilai sig 2 tailed $0,000(\mathrm{P}<0,05)$ yang artinya terdapat pengaruh metode mnemonic terhadap kepatuhan ibu dalam mengkonsumsi Pil KB Di Kecamatan Ngimbang Kabupaten Lamongan. Metode mnemonic merupakan salah satu alternatif yang dapat digunakan ibu untuk meningkatkan daya ingat ibu untuk minum Pil KB sesuai jadwal.
\end{abstract}

Kata kunci : Mnemonic, Kepatuhan, Pil KB

\begin{abstract}
Oral contraceptive pill is one of the contraceptives that are in great demand by family planning acceptors because they are very effective and fertility can return immediately if use is discontinued, but the failure rate is also quite high due to non-adherence to the schedule for taking Oral contraceptive pill. Therefore we need an appropriate method to improve adherence so that the failure rate can be minimized. The purpose of this study was to determine the effect of the mnemonic method on maternal adherence in consuming oral contraceptive pills in Ngimbang, Lamongan Regency.

The research design used a pre-experimental design with a one group pre-test and post-test design approach. The population is all mothers who consume Oral contraceptive pill in Ngimbang Lamongan village with a total sample of 33 family planning pill acceptors taken based on simple random sampling. The instrument used an open questionnaire and the data were analyzed using the MC Nemar test.

The results showed that before the mnemonic method was given, the majority of the 33 respondents (64\%) did not comply with taking Oral contraceptive pill. After being
\end{abstract}


given the mnemonic method, almost all (94\%) were obedient in taking Oral contraceptive pill. Based on the above results, the value of sig 2 tailed is $0.000(P<0.05)$, which means that mnemonic method is effective to increase on maternal adherence in consuming oral Contraceptive pill in Ngimbang District, Lamongan Regency. The mnemonic method is an alternative that can be used by mothers to improve their memory to take oral pills according to the schedule.

Keywords : Mneumonic, adherence, oral Contraceptive pill

\section{PENDAHULUAN}

Program keluarga berencana merupakan salah satu strategi untuk mengurangi angka kematian ibu khususnya kondisi ibu dengan $4 \mathrm{~T}$ terlalu muda melahirkan (usia di bawah 20 tahun), terlalu sering melahirkan, terlalu dekat jarak melahirkan, dan terlalu tua melahirkan (di atas usia 35 tahun). Salah satu program KB yang banyak diminati adalah KB Pil. (Kemenkes, 2016). KB pil merupakan alat kontrasepsi yang banyak digunakan karena metode ini efektif untuk mencegah kehamilan dan salah satu metode yang di sukai karena kesuburan langsung kembali bila pengguanaan dihentikan (Everett, 2015). Meskipun banyak manfaat, keterjangkauan dan kemudahan penggunaan, kepatuhan terhadap pil masih relatif rendah (Molloy, Graham, \& McGuinness, 2012). KB Pil seharusnya di konsumsi setiap hari tetapi pada ibu-ibu berisiko terlupakan pada waktu tertentu pada saat ada kesibukan dan banyak ibu-ibu yang tidak patuh mengkonsumsi Pil KB. Kepatuhan yang kurang sempurna ini mengurangi efektivitas pil menjadi hanya 91\%, berkurang dari 99,7\% (Trussell, 2011).

Menurut WHO tahun 2018 akseptor Pil KB di dunia mencapai 150 juta dengan presentase kegagalan mencapai $(11,26 \%)$.
Menurut data Kemenkes RI jumlah peserta $\mathrm{KB}$ aktif di Indonesia pada tahun 2018 yaitu 23.606.218 orang, akseptor Pil KB sebesar 4.692 orang $(17,24 \%)$ dengan angka kegagalan (52\%). Data dinkes provinsi jatim proporsi peserta $\mathrm{KB}$ aktif pada tahun 2018 yaitu 6.040.011 orang, akseptor Pil KB sebesar 1.163 .375 orang $(12,6 \%)$ dengan angka kegagalan (12,9\%). Sedangkan di Dinkes Kabupaten Lamongan proporsi peserta KB aktif pada tahun 2018 yaitu 237.710 orang, akseptor Pil KB sebesar 61.448 orang $(27,1 \%)$ dengan angka kegagalan (7\%) dan di Kecamatan Ngimbang proporsi peserta kb aktif pada tahun 2018 yaitu 7.017 orang, akseptor Pil KB sebesar 1.065 orang (17\%) denga angka kegagalan $(7 \%)$.

Ada beberapa faktor yang mempengaruhi kepatuhan ibu dalam mengkonsumsi pil KB diantaranya pengetahuan, pendidikan, dukungan keluarga, sikap, motivasi, pekerjaan. Akseptor KB yang tidak patuh mengkonsumsi Pil KB menyebabkan hormon yang terkandung dalam Pil KB tidak bisa bekerja dengan maksimal sehingga berpeluang lebih besar untuk mengalami kegagalan/ kehamilan. Sehingga memerlukan penanganan untuk mengurangi 
ketidakpatuhan ibu mengkonsumsi Pil KB (Dinkes, 2018). Oleh karena itu diperlukan suatu metode untuk membantu akseptor meningkatkan kepatuhan dalam mengkonsumsi pil KB diantaranya metode mneumonic. Metode ini kita kenal dengan istilah jembatan keledai merupakan suatu alat atau cara untuk membantu mempermudah kita dalam menghafal atau mengingat sesuatu. Mnemonic adalah suatu strategi yang digunakan untuk mengingat yang mengunakan asosiasi familiar untuk mempertinggi penyimpanan dan pemanggilan kembali informasi dalam memori. Mnemonic biasanya mengunakan alat verbal terkadang mengunakan sejenis sajak kecil atau kata khusus untuk mengingat sesuatu terkadang juga mengunakan alat visual kinestik, ataupun audio (Huda, 2013).

Penelitian yang dilakukan oleh Yokhanan (2016) didapatkan hasil penelitian menunjukkan sebelum pemberian metode mnemonic seluruhnya 28 responden dengan kriteria daya ingat cukup dan setelah diberikan metode mnemonic sebanyak 24 siswa $(85,7 \%)$ dalam kriteria tinggi, 3 siswa $(10,71 \%)$ dalam kriteria cukup, 1 siswa $(3,58 \%)$ dalam kriteria sangat tinggi. Namun penelitian Mengenai metode mnemonic untuk membantu ibu mengingat jadwal minum pil KB belum banyak diteliti. Sehingga peneliti tertarik untuk melakukan penelitian dengan judul "Pengaruh Metode Mnemonic Terhadap Kepatuhan Ibu Mengkonsumsi Pil KB di Kecamatan Ngimbang Kabupaten Lamongan”.

\section{METODE}

Desain penelitian menggunakan preeksperiment design dengan pendekatan one group pretest-posttest design. Populasinya seluruh ibu yang mengkonsumsi pil KB di Kecamatan Ngimbang Kabupaten Lamongan pada 35 ibu dengan jumlah sampel sebanyak 33 akseptor KB Pil yang diambil dengan menggunakan tehnik simple random sampling. Metode mnemonic yang digunakan dengan menggunakan rymeatau sajak yang dibaca dan rekam lalu dengarkan satu hari sekali selama 1 minggu. Instrument menggunakan kuesioner terbuka dan data dianalisis dengan menggunakan uji $M C$ Nemar.

\section{HASIL DAN PEMBAHASAN}

1. Karakteristik Responden

Tabel 1. Distribusi frekuensi karakteristik akseptor KB Pil

\begin{tabular}{llll}
\hline \multicolumn{2}{c}{$\begin{array}{c}\text { Karakteristik akseptor KB } \\
\text { Pil }\end{array}$} & $\mathrm{N}$ & $\%$ \\
\hline usia & $21-30$ tahun & 5 & 15 \\
\cline { 2 - 4 } & $31-40$ tahun & 18 & 55 \\
\cline { 2 - 4 } & $>40$ tahun & 10 & 30 \\
\hline pendidikan & SD & 4 & 12 \\
\cline { 2 - 4 } & SMP & 9 & 27 \\
\cline { 2 - 4 } & SMA & 19 & 58 \\
\cline { 2 - 4 } & Perguruan & 1 & 3 \\
\hline Pekerjaan & Tinggi & 4 & 12 \\
\cline { 2 - 4 } & Pedagang & 11 & 33 \\
\cline { 2 - 4 } & Wiraswasta & 12 & 36 \\
\cline { 2 - 4 } & Petani & 6 & 18 \\
\cline { 2 - 4 } & Swasta & 11 & 33 \\
\hline Paritas & primipara & & \\
\hline
\end{tabular}




\begin{tabular}{llcc}
\hline multipara & 21 & 64 \\
\cline { 2 - 3 } grandemultipara & 1 & 3 \\
\hline
\end{tabular}

Berdasarkan tabel 1 menunjukkan mayoritas akseptor KB Pil berusia 31-40 tahun $(55 \%)$, Pendidikan akseptor sebagian besar pada tingkat SMA (58\%), sedangkan pekerjaan akseptor mayoritas sebagai petani dan untuk paritas sebagian besar akseptor termasuk kategori multipara.

\section{Kepatuhan Ibu Yang Mengkonsumsi Pil}

\section{$\mathrm{KB}$}

Tabel 2. Distribusi frekuensi kepatuhan akseptor KB Pil sebelum dan sesudah diberikan metode mneumonic

\begin{tabular}{clcc}
\hline No & Kepatuhan & $\mathrm{N}$ & $\%$ \\
\hline \multirow{2}{*}{ pre } & Patuh & 12 & 36 \\
\cline { 2 - 4 } & Tidak Patuh & 21 & 64 \\
\hline \multirow{2}{*}{ post } & Patuh & 32 & 94 \\
\cline { 2 - 4 } & Tidak Patuh & 2 & 6 \\
\hline \multicolumn{2}{c}{ Total } & 33 & 100 \\
\hline
\end{tabular}

Berdasarkan tabel 2 menunjukan bahwa sebelum diberikan metode mneumonic, mayoritas (64\%) akseptor KB Pil tidak patuh dalam mengkonsumsi Pil KB, namun setelah diberikan metode mneumonic kepatuhan akseptor KB Pil meningkat prosentasenya hingga $96 \%$.

3. Pengaruh metode mnemonic terhadap kepatuhan ibu yang mengkonsumsi Pil $\mathrm{KB}$

Tabel 3. Tabulasi silang pengaruh metode mneumonic terhadap kepatuhan akseptor KB Pil setelah diberikan metode mneumonic

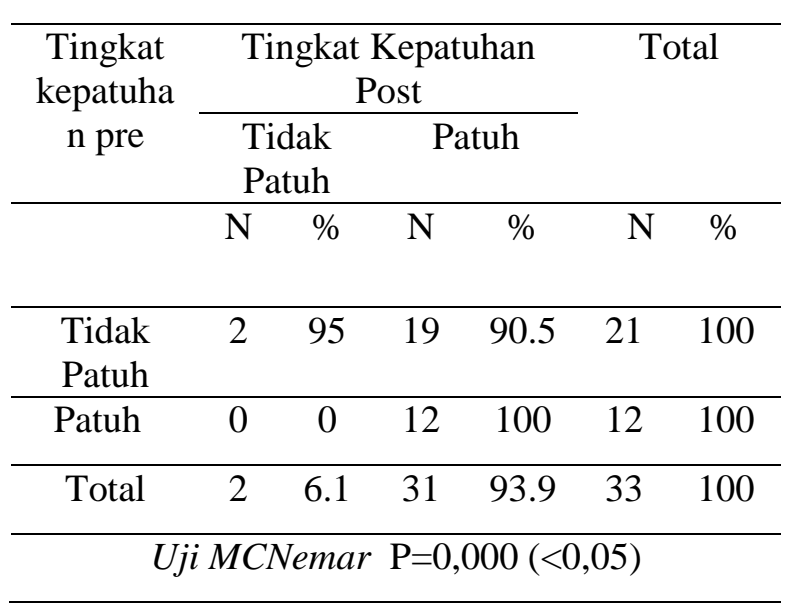

Berdasarkan tabel 3 menunjukan bahwa akseptor Pil KB yang sebelumnya patuh dalam mengkonsumsi pil KB, seluruhnya (100\%) tetap patuh, sedangkan akseptor KB yang seblumnya tidak patuh, sebagian besar (90.5\%) menjadi patuh. Data ini diperkuat oleh uji statistic dengan menggunakan Mc.Nemar dengan nilai $\alpha=$ $0.05 \%$ di dapatkan nilai $\mathrm{P}=0.000(<0.05)$. hal ini dapat disimpulkan bahwa ada pengaruh metode mneumonic terhadap kepatuhan akseptor dalam mengkonsumsi Pil KB.

\section{PEMBAHASAN}

Hasil penelitian menunjukan bahwa tingkat kepatuhan ibu dalam mengkonsumsi Pil KB sebelum diberikan metode mnemonic sebagian besar (64\%) tidak patuh. Hal tersebut dapat di pengaruhi oleh beberapa faktor diantaranya pekerjaan. Berdasarkan tabel 1 menunjukan bahwa hampir sebagian (36\%) ibu yang mengkonsumsi Pil KB bekerja sebagai petani. Pekerjaan adalah sesuatu yang di lakukan untuk mencari nafkah atau pencaharian. Masyarakat yang sibuk dengan kegiatan atau pekerjaan sehari- 
hari akan memiliki waktu yang lebih sedikit untuk memperoleh informasi (Soekidjo, 2014). Keaktifan ibu dalam membantu meningkatkan penghasilan keluarga, membuat ibu lebih fokus terhadap pekerjaan dalam hal ini petani yang bekerja dari pagi sampai sore sehingga sampai rumah ibu akan langsung istirahat bahkan lupa jadwal mengkonsumsi Pil KB yang secara tidak langsung berpengaruh terhadap kepatuhan ibu dalam mengkonsumsi Pil KB, faktor lain yang terkait dengan tingkat kepatuhan akseptor dalam mengkonsumsi pil KB adalah pengetahuan tentang pil, baik yang dirasakan (Tomaszewski et al., 2017) dan aktual (Hall, Castaño, \& Westhoff, 2014).

Kedua penelitian menunjukkan bahwa wanita yang melaporkan percaya bahwa mereka memiliki pengetahuan yang lebih tinggi tentang pil atau benar-benar menunjukkan pengetahuan yang lebih besar, melaporkan tingkat kepatuhan yang lebih tinggi dan niat untuk terus minum pil (Hall et al., 2014; Tomaszewski et al., 2017). Wanita dengan pengetahuan yang lebih tinggi tentang cara kerja pil, manfaat, efek samping, dan penggunaannya hingga 6 kali lebih mungkin untuk terus minum pil dibandingkan dengan wanita yang kurang berpengetahuan (Hall et al., 2014). Caitlin (2020) juga menemukan hubungan positif yang signifikan antara literasi kesehatan dan kepatuhan. Literasi kesehatan adalah prediktor yang paling signifikan dari kepatuhan terhadap pil kontrasepsi oral tanpa pengetahuan maupun interaksi antara literasi kesehatan dan prediktor yang signifikan pengetahuan. literasi Kesehatan dapat meningkatkan pengetahuan tentang pil kontrasepsi oral dan memahami bagaimana cara memakai pil dengan benar, sehingga hal ini bisa meningkatkan kepatuhan (Molloy, G, 2012). Dan setelah diberikan metode mneumonic Sebagian besar menjadi patuh (90.5\%). Hubungan ini konsisten dengan penelitian sebelumnya yang juga menemukan hubungan yang signifikan antara literasi kesehatan dan kepatuhan pengobatan di berbagai penyakit kronis (Mayo-Gamble \& Mouton, 2018; Miller, 2016; Osborn et al., 2011; Zhang et al., 2014). Hasil uji McNemar juga menyatakan ada pengaruh yang signifikan penggunaan metode mneumonic terhadap kepatuhan akseptor KB Pil.

Metode mneumonic merupakan teknik atau sebuah perangkat verbal dan visual yang dapat meningkatkan kapasitas ingatan seseorang dan mengingat informasi baru dengan mudah (Siriganjanavong, 2013). Bahwa mnemonik adalah sebuah teknik atau alat yang dapat membantu ingatan seseorang dengan cara mentransfer materi kedalam format yang mudah dipelajari dan diingat dengan memanfaatkan otak manusia untuk memaksimalkan ingatan sehingga dapat membantu seseorang dalam mengingat informasi dan menjadikan informasi tersebut tersimpan dalam ingatan jangka panjang. Mnemonik berhubungan dengan imajinasi seseorang dan bagaimana ia mengasosiasikannya, karena asosiasi ini akan memancing ingatan bahkan dalam jangka waktu yang lama. Secara kasar, mnemonik memaksa seseorang untuk 
mengkoordinasikan otak kanan dan otak kiri secara maksimal (Risna 2018). Cara-cara yang dilakukan untuk pengkordinasian beragam, misalnya dengan membuat cerita, menghubungkan dan menvisualisasikan kata, sajak, membuat ide dan khayalan.

Peneliti memberikan metode mnemonic yaitu metode akseptor Pil KB untuk mengingat dengan cara mendengarkan memberikan sajak pil $\mathrm{KB}$ dalam sebuah alarm yang di gunakan untuk ringtone nada alarm. Responden di minta untuk mengingat saat ringtone berbunyi. Dengan demikian diharapkan metode mnemonic dapat meningkatkan daya ingat akseptor dengan cara mengunakan asosiasi familiar untuk memepertinggi penyimpanan dan pemangilan kembali informasi dalam memori dalam waktu jangka panjang. Hal ini dibuktikan dari hasil penelitian yang menunjukkan bahwa respon akseptor terhadap keptuhan dalam mengkonsumsi pil $\mathrm{KB}$ meningkat setelah diberikan metode menumonik. Kepatuhan dalam hal ini bahwa akseptor patuh terhadap jadwal atau jam mengkonsumsi pil KB, karena sejatinya Pil KB harus diminum tiap hari di jam yang sama dan dikatakan patuh jika ibu minum Pil KB tidak melebihi 12 jam jadwal minum Pil KB (Hartanto, 2015).

Studi lain yang dilakukan Yokhanan (2016) menunjukkan setelah diberikan metode mnemonic Sebagian besar (85,7\%) mempunyai kriteria tinggi. Peningkatan kepatuhan akseptor selain karena metode mneumonic yang efektif juga di tunjang factor paritas. berdasarkan tabel 1 sebagian besar (64\%) ibu yang mengkonsumsi Pil KB mempunyai 2-3 anak. Paritas yang tinggi apalagi dengan adanya pengalaman minum pil KB sebelumya akan membuat daya ingat meningkat. hal tersebut dapat mempengaruhi tingkat kepatuhan ibu dalam mengkonsumsi Pil KB. Metode mnemonic merupakan cara mengingat dengan melibatkan otak kanan sehingga informasi akan tersimpan lebih lama dan mudah untuk dipanggil kembali karena tersimpan dalam memori jangka panjang (Long Term Memory) (SGM,2008).

\section{PENUTUP}

Berdasarkan penelitian dan pembahasan serta tujuan dari penelitian maka dapat disimpulkan bahwa penggunaan metode mnemonic mampu meningkatkan kepatuhan akseptor dalam mengkonsumsi Pil KB di Kecamatan Ngimbang Kabupaten Lamongan. Metode mnemonic dapat digunakan sebagai salah satu alternatif yang dapat digunakan ibu untuk meningkatkan daya ingat ibu untuk minum Pil KB sesuai jadwal.

\section{DAFTAR PUSTAKA}

Caitlin Liddelow, Barbara Mullan \& Mark Boyes (2020) Adherence to the oral contraceptive pill: the roles of health literacy and knowledge, Health Psychology and Behavioral Medicine, 8:1, 587-

600, DOI: $10.1080 / 21642850.2020 .18$ $\underline{50288}$

Dinas Kesehatan. (2018), Profil Kesehatan Kabupaten Lamongan 2018. Lamongan: Dinkes Kabupaten Lamongan 
Dinas Kesehatan. (2017), Profil Kesehatan Provinsi Jawa Timur 2016. Surabaya: Dinkes Jatim

Everett, \& Suzanne. (2015). Buku Saku Kontrasepsi \& Kesehatan Seksual Reproduktif, Jakarta: Penerbit Buku Kedokteran EGC

Hartanto, Hanafi. (2015). Keluarga Berencana dan Kontrasepsi, Jakarta: Penerbit Pustaka Sinar Harapan

Hall, K. S., Castaño, P. M., \& Westhoff, C. L. (2014). The influence of oral contraceptive knowledge on oral contraceptive continuation among young women. Journal of Women's Health, 23(7), 596-601.

doi:10.1089/jwh.2013.4574 [Crossref], [PubMed], [Web of Science (B], [Google Scholar]

Kemenkes RI, (2018), Profil Kesehatan Indonesia 2016. Jakarta: Kementrian Indonesia

Mayo-Gamble, T. L., \& Mouton, C. (2018). Examining the association between health literacy and medication adherence among older adults. Health

Communication, 33(9), 1124-1130. doi:10.1080/10410236.2017.1331311 [ Taylor \& Francis Online], [Web of Science ${ }^{\circledR}$, [Google Scholar]

Mifatkhul Huda, Model-model Pengajaran, (Yogyakarta:Pustaka Pelajar, 2013),

Miller, T. A. (2016). Health literacy and adherence to medical treatment in chronic and acute illness: A metaanalysis. Patient Education and Counseling, 99(7), 1079-1086. doi:10.1016/j.pec.2016.01.020 [Crossr ef], [PubMed], [Web of Science (], [Google Scholar]

Molloy, G.

J., Graham, H., \& McGuinness, H. (2012). Adherence to the oral contraceptive pill: A crosssectional survey of modifiable behavioural determinants. BMC Public Health, 12, 838. doi:10.1186/14712458-12-
838 [Crossref], [PubMed], [Web of Science ${ }^{\circledR}$ ], [Google Scholar]

Osborn, C. Y., Cavanaugh, K., Wallston, K. A., Kripalani, S., Elasy, T.

A., Rothman, R. $\quad$ L., $\quad$ \& White, R. O. (2011). Health literacy explains racial disparities in diabetes medication adherence. Journal of Health Communication, 16, 268-278. doi:10.1080/10810730.2011.604388 [ Taylor \& Francis Online], [Web of Science ${ }^{\circledR}$ ], [Google Scholar]

Risna Rianti Sari, (2018). Mnemonik Sebagai Alternatif Dalam Menghafal Kosakata Bahasa Arab Mahasiswa. Jurnal Tarbiyatuna Volume 3 Nomor 2 (Desember) 2018 Hlm. 30 - 50

SGM, Mr. (2008). Super Great Memory. Jakarta : Gramedia Pustaka Utama

Siriganjanavong, V.(2013).The Mnemonic Keyword Method: Effects on the Vocabulary Acquisition and Retention. (English Language Teaching, 2013) 6(10) https://doi.org/10.5539/elt.v6n10p1

Soekidjo , Notoatmodjo. (2014). Promosi kesehatan dan Perilaku Kesehatan. Jakarta : Rineka cipta Kedelapan. Jakarta: Erlangga

Tomaszewski, D., Aronson, B.

D., Kading, M., \& Morisky, D. (2017). Relationship between self-efficacy and patient knowledge on adherence to oral contraceptives using the Morisky medication adherence scale (MMAS8). Reproductive Health, 14, 110. doi:10.1186/s12978-017-0374-

6 [Crossref], [PubMed], [Web of Science ${ }^{\circledR}$ ], [Google Scholar]

Trussell, J.. (2011). Contraceptive failure in the United States. Contraception, 83(5), 397404. http://doi.org/10.1016/j.contracept ion.2011.01.021 [Crossref], [PubMed], [Web of Science (], [Google Scholar]

Yokhanan, A. (2016). Efektivitas Metode Mnemonik Ditinjau dari Daya Ingat dan Hasil Belajar Matematika Siswa 
SMK Kelas X. Jurnal Matematika.

Semarang: Universitas Negeri

Semarang

Zhang, N. J., Terry, A., \& McHorney, C.

A. (2014). Impact of health literacy on medication adherence: A systematic review and meta-analysis. Annals of Pharmacotherapy, 48(6), 741-751.

doi:10.1177/1060028014526562 [Cros

sref], [PubMed], [Web of Science

(B], [Google Scholar] 